\title{
Museu da inconfidência e as marcas da educação nos livros de visitantes (1945-1965)
}

Museum of inconfidence and the marks of education in the visitors's books (1945-1965)

Museo de la inconfidencia y las marcas de la educación en los libros de visitantes (1945-1965)

\author{
Betânia dos Anjos do Carmo \\ Universidade Federal de Ouro Preto (Brasil) \\ https://orcid.org/0000-0002-2477-732X \\ http://lattes.cnpq.br/9204430058462159 \\ betania.dosanjos@yahoo.com.br \\ Juliana Cesário Hamdan \\ Universidade Federal de Ouro Preto (Brasil) \\ https://orcid.org/0000-0002-3078-4876 \\ http://lattes.cnpq.br/9913625333771045 \\ julianach62@gmail.com \\ Rosana Areal de Carvalho \\ Universidade Federal de Ouro Preto (Brasil) \\ https://orcid.org/0000-0002-0114-4239 \\ http://lattes.cnpq.br/0015367380312522 \\ rosanareal@ufop.edu.br
}

\section{RESUMO}

Este artigo se originou de uma pesquisa, cujo principal objetivo foi o de identificar, quantificar e analisar, no Museu da Inconfidência, localizado na cidade de Ouro Preto, Minas Gerais, a presença de sujeitos auto declarados escolares. Para isso, foram utilizados como fontes, cartas e ofícios encaminhados por professores e diretores de escolas, direcionados aos diretores do Museu, e os livros com as assinaturas dos visitantes, fontes privilegiadas nesta pesquisa. Trata-se de uma fonte original ainda pouco explorada pelas pesquisas no campo da História e da História da Educação. O período definido para este estudo compreendeu os anos de 1945, quando o museu foi inaugurado, e 1965, quando se iniciou uma nova fase política, com a instauração da ditadura, em que se observa modificações nos discursos culturais, de forma geral, e educacionais, de forma particular. As análises foram feitas a partir dos levantamentos quantitativos dos visitantes autodeclarados estudantes e professores, ou ligados a instituições de ensino. Observou-se a predominância de um maior número de visitantes ligados a instituições particulares e religiosas, e um registro significativo de visitantes de escolas militares, enquanto a presença de sujeitos ligados à escola pública, mesmo as geograficamente próximas, foi bem rarefeita.

Palavras-chave: Museu da Inconfidência. História da educação. Livros de visitantes. 


\begin{abstract}
This article originated from a research, whose main objective was to identify, quantify and analyze, in the Museum of the Inconfidência, located in the city of Ouro Preto, Minas Gerais, the presence of self - declared school subjects. For this purpose, oficial letters sent by teachers and school principals, directed to the directors of the Museum, and the books with the signatures of the visitors, privileged sources in this research, were used. It is an original source still little explored by research in the field of History and History of Education. The period defined for this study comprised the years 1945, when the museum was inaugurated, and 1965, when a new political phase began, with the establishment of the dictatorship, in which there are changes in cultural discourses, in general, and educational, in particular. The analyzes were made from the quantitative surveys of self-declared visitors to students and teachers, or linked to educational institutions. Thus, the predominance of a greater number of visitors connected to private and religious institutions and a significant number of visitors to military schools was observed, while the presence of the the presence of subjects connected to the public school, even those geographically close, was very rarefied.
\end{abstract}

Keywords: Museum of Inconfidence. History of education. Books of visitors.

\title{
RESUMEN
}

Este artículo se originó de una investigación, cuyo principal objetivo fue identificar, cuantificar y analizar, en el Museo de la Inconfidencia, ubicado en la ciudad de Ouro Preto, Minas Gerais, la presencia de sujetos auto declarados escolares. Para ello, fueron utilizados como fuentes, cartas y oficios encaminados por profesores y directores de escuelas, dirigidos a los directores del Museo, y los libros con las firmas de los visitantes, fuentes privilegiadas en esta investigación. El período definido para este estudio comprendió los años de 1945, cuando el museo es inaugurado, y 1965, cuando se inició una nueva fase política, con la instauración de la dictadura, en que se observa en los discursos culturales, de forma general, y educativas de forma particular. Los análisis se realizaron a partir de las encuestas cuantitativas de los visitantes auto declarados estudiantes y profesores, el vinculados a instituciones de enseñanza. Se observó, así, la predominancia de un mayor número de visitantes ligados a instituciones particulares y religiosas, y un registro significativo de visitantes de escuelas militares, mientras que la presencia de sujetos ligados a la escuela pública, incluso las geográficamente próximas, fue muy escasa.

Palabras clave: Museo de la Inconfidencia. Historia de la educación. Libros de visitantes. 


\section{O imaginário coletivo e o museu}

Para além das novas leis voltadas à educação na primeira metade do século XX, surgiram também articulações vinculadas à cultura, criadas para a preservação do patrimônio histórico nacional. Foi um período em que, historicamente, despontou, na cena pública brasileira, uma preocupação com a preservação da memória do país, culminando em debates que refletiram, em alguma medida, nos textos legais, a partir da década de 1930, e que mais tarde, acabaram por influírem na criação de instituições de apoio e defesa do patrimônio. Como uma evidência dessa ambiência esteve a criação de museus nacionais e o aumento gradativo de visitantes em geral, e aqueles ligados a instituições escolares, em particular, como pudemos atestar nos livros de visitantes do Museu da Inconfidência, fonte privilegiada na pesquisa que deu origem a este artigo.

Ouro Preto, como se sabe, foi palco de acontecimentos que se moldaram por meio de elementos que representam determinada narrativa de parte das memórias nacionais, dentre as quais destaca-se o evento conhecido como Inconfidência Mineira, episódio que ganhou muita relevância histórica, ao ponto de merecer um museu de mesmo nome. Dessa forma, a motivação de instituições educacionais para procurar o museu sempre foi bastante justificada, sobretudo se levarmos em consideração presença do tema nos livros escolares, no ensino de História do Brasil, o estilo de arquitetura barroca da cidade, sua relação com acontecimentos históricos ligados às questões cívicas e patrióticas, o período da extração mineral do ouro, a relação e formação da cidade com o tráfico de africanos, entre outros motivos.

Se os republicanos fizeram de Tiradentes um herói nacional, foi posteriormente, já na Era Vargas que essa história criou força e vigor. A partir dos anos 40 do século XX, a imprensa brasileira produziu um extenso material impresso sobre a Inconfidência Mineira e seu "herói". Essa divulgação contribuiu para o processo de consolidação das representações consideradas como relevantes para os ideais republicanos. Nesse sentido, dentre aqueles que assinaram os artigos veiculados entre as décadas de 1930 e 1960, estavam alguns dos mais notáveis intelectuais brasileiros, tais como Manuel Bandeira ${ }^{1}$, Augusto de Lima Júnior, Gustavo Barroso, Carlos Drummond de Andrade, Rodrigo Melo Franco de Andrade, entre muitos outros. Não obstante a riqueza histórica e arquitetônica, certamente a ampla divulgação contribuiu para dar visibilidade e notoriedade à cidade e seu patrimônio, motivando as pessoas a visitarem-na, bem como ao museu, registrando-se, inclusive, a presença de muitos estrangeiros.

A prática de se divulgar as cidades históricas tinha também como objetivo ampliar o potencial turístico no país e também no exterior. Exemplo disso foi um documento datado de 05 de junho de 1956, já com onze anos de existência, assinado pelo Diretor do Museu, Cônego Raimundo Otávio Trindade, agradecendo ao Jornal do Comércio "[...] pela divulgação das notas anteriores [...]" sobre o museu. Por meio dessas ações, paulatinamente, o Museu da Inconfidência foi sendo erigido como uma das principais memórias históricas a serem preservadas e valorizadas como sendo constituintes de um determinado ideal de nação e de representação de povo, como sendo destemido, livre e corajoso. Tal memória foi robustecida, sobretudo, pela figura de Tiradentes, antes considerada um réu e que foi, gradativamente, transformado em mártir e herói da nação.

1 O Guia de Ouro Preto, escrito por Manuel Bandeira é um bom exemplo destas articulações que contribuíram para difundir a cidade do ouro e colocá-la como referência no circuito histórico e turístico do país. O professor Luís Romano assevera que o Guia: “[...] foi uma solicitação do Serviço do Patrimônio Histórico e Artístico Nacional, atual Instituto (IPHAN), criado em 1937, no Governo Vargas. [...] artigo adaptado do Guia de Ouro Preto, é publicado na revista Travel in Brazil [...] e financiada pelo Departamento de Imprensa e Propaganda (DIP) de Vargas" (ROMANO, 2017, p. 1129). 
Em suas reflexões, o historiador José Murilo de Carvalho assevera que, para se criar um mito é preciso trabalhar o imaginário social, afirmando que "[...] a elaboração de um imaginário é parte integrante da legitimação de qualquer regime político" (CARVALHO, 1990, p. 10). Não foi diferente com a Inconfidência Mineira. Carvalho ressalta ainda que: "É por meio do imaginário que se pode atingir não só a cabeça mas, de modo especial, o coração, isto é, as aspirações, os medos e as esperanças de um povo. É nele que as sociedades definem suas identidades e objetivos, definem seus inimigos, organizam seu passado, presente e futuro" (CARVALHO, 1990, p. 10).

Nos livros de visitação, identificamos muitas vezes o registro de pessoas que deixaram escritas em suas páginas a sua admiração pelos Inconfidentes, elogiando a coragem e bravura de Tiradentes, parabenizando a iniciativa de se criar um museu para esse fim. Desta forma, conclui-se que a história da Inconfidência Mineira e a imagem de Tiradentes como figura heroica da nação começaram a ser construídas dentro de determinadas concepções históricas e políticas, cujos principais objetivos estavam alinhados aos ideais de constituição de uma nação republicana, livre e civilizada, mas com dispositivos de controle sobre como esta deveria ser imaginada.

Não há como negar que a criação do museu, bem como o fortalecimentos dos mitos e ideais patrióticos arrolados neste processo foram extremamente importantes para o país. Entretanto, paradoxalmente, também serviu como um dispositivo de sombreamento de contradições e, até mesmo, dispersão de potenciais forças transgressoras. Neste sentido, podemos apontar que a estratégia para criação do Museu da Inconfidência não foi somente para preservar a memória da nossa história, mas também para produzir determinados esquecimentos, ou seja, para que determinados grupos conquistassem os respectivos projetos de poder. Jacques Le Goff (1984) afirma que, para os protagonistas desses projetos ocupar os lugares de "[...] senhores da memória e do esquecimento, é uma das grandes preocupações das classes, dos grupos, dos indivíduos que dominaram e dominam as sociedades históricas. Os esquecimentos e os silêncios da história são reveladores desses mecanismos de manipulação da memória coletiva" (LE GOFF, 1984, p. 103).

\section{Os ofícios vindos das escolas}

Conforme anunciamos, a fonte privilegiada neste estudo foram os livros de visitação do museu, a partir do volume I, chegando ao volume 26 . Tomando o primeiro livro, que é datado de 29 de dezembro de 1945, prosseguimos na coleta de dados até dezembro 1965, e incluímos ainda um livro de visitantes ilustres, que foi utilizado à parte, completando, assim, um total de 27 (vinte e sete) livros pesquisados ${ }^{2}$. No mesmo local onde estavam os livros, foram localizados também documentos administrativos tais como ofícios, cartas e correspondências, enviados ao museu por instituições escolares, na pessoa de seus representantes diretores, professores, alunos, além de militares e religiosos, todos esses vinculados a escolas públicas, particulares, militares, religiosas, profissionalizantes. Encontramos ainda algumas cartas de entidades educativas de formação não escolar, como, por exemplo, grupos de escoteiros.

A questão principal era a de identificar, quantificar, qualificar e analisar, qual o tipo de público visitante escolarizado procurava esse espaço cultural, que abriga, até os dias de hoje, uma parte importante da história do Brasil, com a exposição permanente sobre a Inconfidência Mineira, bem como objetos que representam os costumes do período ali representado. Alguns dos documentos encontrados, como as correspondências enviadas por

\footnotetext{
${ }^{2}$ Esse material encontra-se localizado no Anexo III do Museu da Inconfidência, também conhecido como Casa do Pilar, local onde estão arquivados os documentos administrativos e históricos da instituição. Trata-se de um conjunto de documentos com enorme potencial de pesquisa histórica, em diversos campos.
} 
instituições escolares ao museu, mostram escolas interessadas em visitá-lo, geralmente pelo fato de estarem estudando algo ligado à Inconfidência Mineira ou mesmo à cidade de Ouro Preto, como mostra o documento abaixo. Com timbre do Departamento de Correios e Telégrafos, originário de uma agência de Mogi das Cruzes, São Paulo, foi enviado pelo Senhor Henrique Rangelo e endereçado ao diretor do Museu (Foto 1). No documento, o remetente solicita ao diretor Orlandino Fernandes ${ }^{3}$ o obséquio de "[...] informar se possível a visita de alunos meu Colégio ao Museu [...] excursão (sic) de História [...]”.

Foto 1 - Telegrama de diretor de escola informando ao Diretor do Museu da Inconfidência, sobre uma excursão com grupo de alunos de Mogi das Cruzes, recebido em 23 de outubro de 1935.

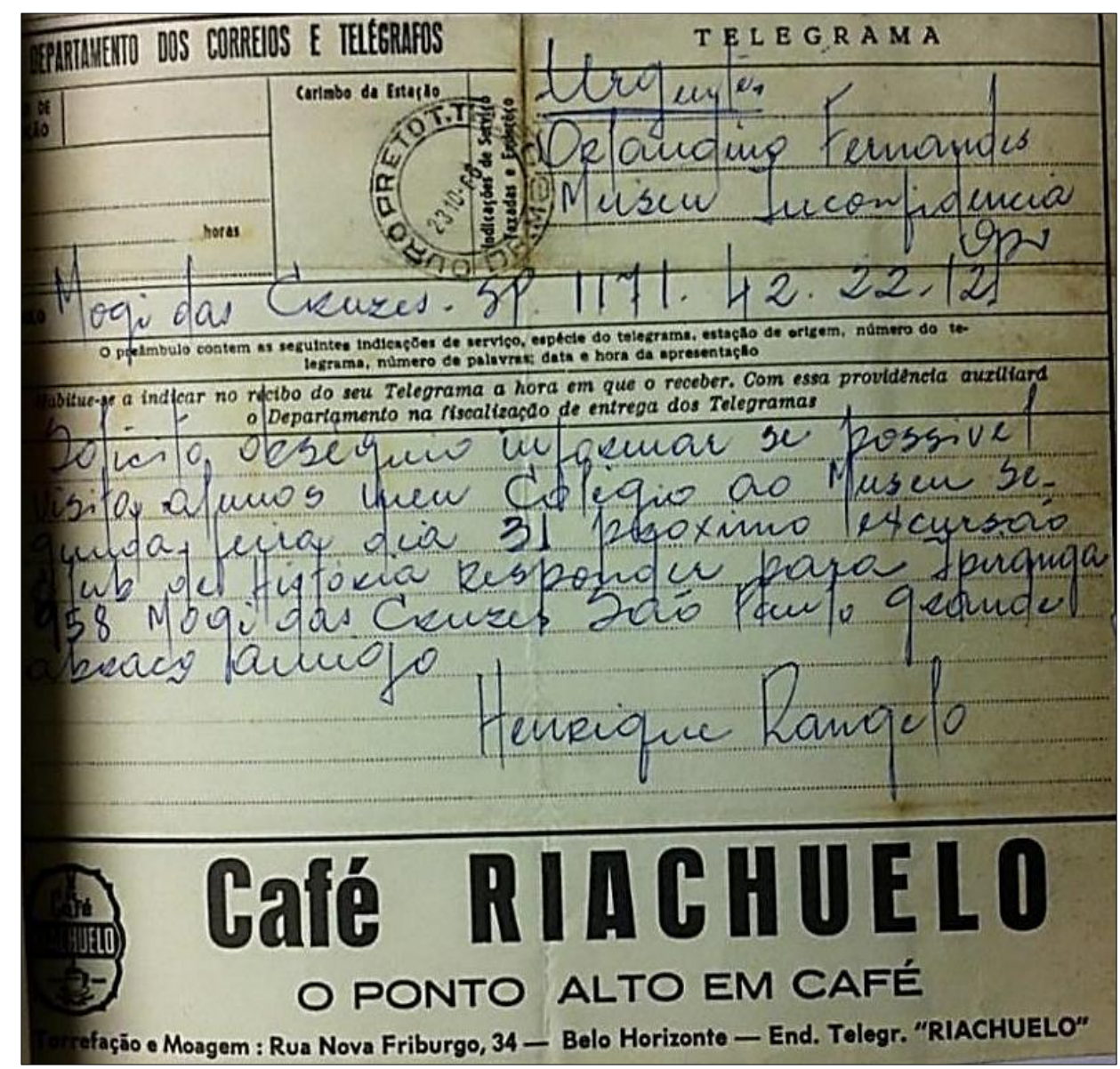

Fonte: Acervo Fotográfico de Betânia dos Anjos do Carmo - 2018

Muitas correspondências semelhantes a essa foram localizadas nos arquivos da Casa do Pilar, o que demonstra um grande interesse das instituições escolares, no período enfocado, em procurar esse espaço para algum tipo de atividade prevista ou complementar ao currículo, com seus alunos. De igual maneira, vê-se também que o museu procurava atender e receber esses grupos apoiando-os nas demais necessidades da viagem, como se pode observar na correspondência encontrada em "documentos enviados" do setor administrativo (Foto 2) em que o referido diretor Orlandino escreve ao Sr. Thomaz Farkas, de São Paulo, informando ter "[...] o máximo prazer em receber alunos Colégio Experimental [...]" e dá outras providências para além de suas funções.

\footnotetext{
${ }^{3}$ Vale ressaltar que, ao longo dos 74 (setenta e quatro) anos de criação do museu, três diretores estiveram à frente da instituição, o Cônego Raimundo Trindade (1883-1962) entre 1944 e 1959, o museólogo Orlandino Seitas Fernandes, entre 1959 e 1973, e por último o advogado Rui Mourão (1929) que dirigiu o Museu de 1973 a 2018, sendo que todos eles parecem ter sido acessíveis e receptíveis às demandas escolares.
} 
Foto 2 - Correspondência do Diretor do Museu confirmando a recepção ao grupo de alunos do Colégio Experimental e dando outras providências acerca da estadia, em 24 de agosto de 1936.

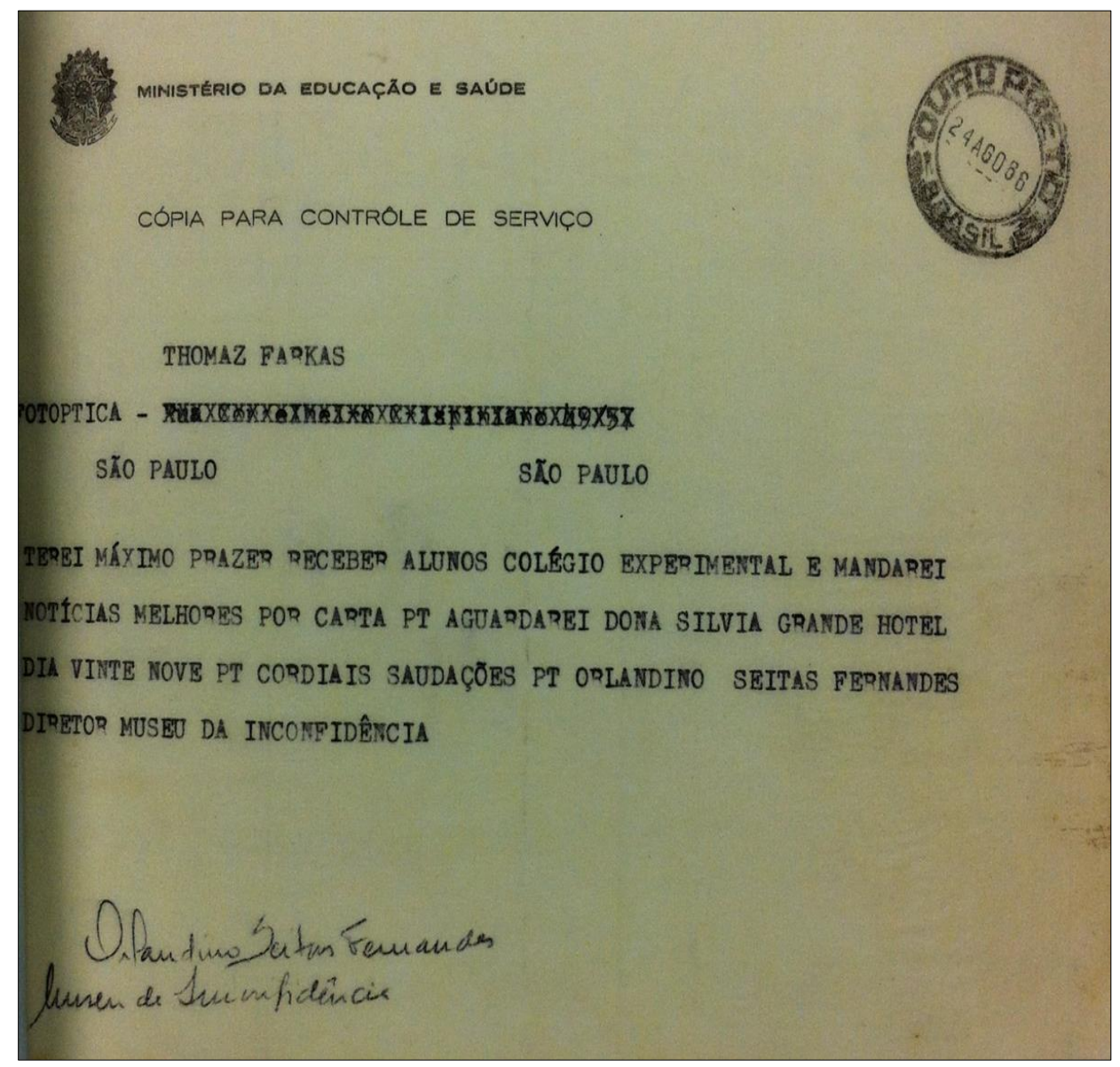

Fonte: Acervo Fotográfico de Betânia dos Anjos do Carmo - 2018

Ainda como exemplo dessa relação cada vez mais robusta entre algumas instituições educacionais e o museu, identificamos nos arquivos uma carta de 25 de junho de 1965, escrita em papel timbrado do Gabinete do Diretor da Faculdade de Filosofia, Ciência e Letras, da Universidade de São Paulo que, em linhas gerais, esclareceu que "[...] O Colégio de Aplicação da Faculdade de Filosofia, Ciência e Letras, da Universidade de São Paulo, procura desenvolver em suas classes de Ginásio um sistema de ensino renovado, a partir da área de Estudos Sociais, que funciona no currículo como área piloto." E ainda uma carta de agradecimento da diretora do Ginásio Estadual Vocacional de Barretos, encaminhada ao diretor do museu "[...] agradecendo-lhe a gentileza com que nos atendeu e o auxílio prestado a nós por ocasião do estudo do meio [...]." Essas trocas de cartas, bastante presentes nos arquivos mencionados, demonstram que diversas instituições escolares procuravam o museu com bastante frequência e este, em contrapartida, se dispunha a atendê-las e acompanhar alunos e professores durante o período da visita.

Outro tipo de fonte encontrado nos documentos localizados na Casa do Pilar, e que foi importante para esse estudo, foram ofícios padronizados, emitidos pelo Museu, referentes ao seu fluxo de visitantes. Como prática comum, esses ofícios, distribuídos sequencialmente desde o ano seguinte à inauguração do museu, em 1945, foram constantes ao longo de todo período enfocado. Foram elaborados, assinados pelos três diretores do museu e direcionados ao "Gabinete de presidência/Diretoria Executiva", cujos destinatários eram os respectivos diretores dos órgãos mantenedores da instituição que, ao longo dos mais de 80 anos, tiveram várias nomenclaturas, tais como o Serviço do Patrimônio Histórico e Artístico Nacional - 
SPHAN, Diretoria Nacional do Patrimônio Histórico - DNPH, Instituto do Patrimônio Histórico e Artístico Nacional - IPHAN, dentre outros, que tinham também como função controlar o fluxo de visitantes.

Como exemplo, destaca-se o ofício 45, de 02 de março de 1956, assinado pelo Cônego Raimundo Otávio Trindade, enviado ao Diretor Geral do IPHAN, Rodrigo Melo Franco de Andrade, cujo assunto era o "Total de visitas do mês de fevereiro/1956: 2.151 visitantes"4. Em resposta, o referido diretor comunica ao diretor do museu, conforme o ofício n. 157, de 08 de março de 1956, em folha timbrada do Ministério da Educação e Saúde - MEC/DPHAN, que tal informação foi encaminhada ao "Chefe de Serviço de Imprensa do MEC, para fins de publicidade na imprensa." Nossa análise não confirma esse número de assinaturas correspondentes ao mês de fevereiro de 1956, nos livros de visitantes. Desse modo, consideramos que, para fins do nosso estudo, qual seja o de caracterizar o público autodeclarado como sendo ligado à instituições escolares, os livros de visitantes constituíramse como uma fonte mais fidedigna. Dessa maneira, foram escolhidos como fonte privilegiada somente os livros de visitação, colocados publicamente à disposição de qualquer visitante no saguão do museu. O registro sequencial, manuscrito, pessoal e quase sempre constante dos livros ao longo dos anos pareceu ser mais fidedigno, por se tratar de apontamentos de próprio punho e por representar de fato a presença do visitante no local e data ali colocados.

\section{Os livros de visitantes do Museu da Inconfidência}

Bernadete Gatti considera que, em educação, “[...] poucos estudos empregam metodologias quantitativas [...]" (GATTI, 2004, p.11). E, por isso mesmo, a autora acredita que "[...] há problemas educacionais que para sua contextualização e compreensão necessitam ser qualificados através de dados quantitativos" (GATTI, 2004, p.11). Dessa forma, fez-se pertinente a proposta metodológica de Gatti para o emprego de um método quantitativo para o tratamento dessas fontes. A partir desses dados e análises numéricas, foi possível alcançarmos interpretações qualitativas, alinhando ao que Gatti defendeu que "[...] a combinação deste tipo de dados com dados oriundos de metodologias qualitativas pode vir a enriquecer a compreensão de eventos, fatos, processos" (GATTI, 2004, p. 11).

Acompanhando as orientações da autora citada, foi feito um levantamento quantitativo do público que visitou o museu a partir das informações solicitadas nos livros, "nome, procedência e data". Após esse primeiro levantamento, foi feita uma seleção minuciosa daqueles que se auto declararam como sendo vinculados, de alguma forma, a uma instituição educacional, podendo ser na condição de diretores, professores e estudantes, dentre outros. Com o isolamento desse público específico, foi possível fazer uma análise mais apurada, do perfil desses visitantes. O maior interesse foi o de estudar quem eram e de onde vinham esses sujeitos que visitavam um museu, no interior das Minas Gerais.

Dos 26 livros de visitantes analisados, presentes entre 1945 e 1965, mais o específico para visitantes ilustres ${ }^{5}$, foi identificado apenas um lapso temporal de cinco meses, entre 08 de março de 1962 e 28 de julho de 1962 (livro 15) e uma duplicidade numérica entre dois livros, o que, porém, não prejudicou a sequência cronológica para a análise, uma vez que os respectivos conteúdos eram distintos.

\footnotetext{
${ }^{4}$ Informações extraídas da Caixa n. 32/Análise de visitação/Ano:1955 a 1964/Pasta: Análise de visitação havida no Museu Inc. durante o ano de 1955 a 1959 (ARQUIVO HISTÓRICO DO MUSEU DA INCONFIDÊNCIA, [19-]).

${ }^{5}$ Nos livros foram encontradas assinaturas que sugerem pertencer a figuras públicas como Carlos Lacerda (1914-1977) e seus filhos, Sebastião Lacerda e Sérgio Carlos Lacerda, os artistas plásticos Alberto da Veiga Guignard (1896-1962) e Amílcar de Castro (1920-2002) e, no livro reservado a visitantes ilustres, foi localizada a assinatura de Juscelino Kubitschek (1902-1976). Localizada também a presença de um grupo de escolares do Colégio Arnaldo de Belo Horizonte, acompanhado de um padre(ARQUIVO HISTÓRICO DO MUSEU DA INCONFIDÊNCIA, [19--], p. 10). Esse foi o colégio em que estudou Gustavo Capanema.
} 
Confeccionados em capa dura, as dimensões dos livros são de $33,5 \mathrm{~cm}$ x $22 \mathrm{~cm}$, todos com duzentas folhas e quatrocentas páginas (frente e verso). No primeiro livro (livro 01), contabilizam-se trinta e uma linhas livres para registro em cada folha, enquanto os demais livros tinham o espaço livre de trinta e duas linhas por folha, podendo registrar cerca de 12.800 (doze mil e oitocentos) visitantes por ano. Todos os livros de visitação possuem também uma paginação numérica e sequencial crescente impressa no canto superior direito de cada folha da frente. De acordo com a relação de livros e datas apresentada acima, nos primeiros anos de abertura do museu, cada livro registrou em média três anos de visitação.

Sabendo da prática interna da instituição ${ }^{6}$ em não se abrir o museu às segundas-feiras para manutenção e limpeza, foi contabilizada uma média de 355 (trezentos e cinquenta e cinco) visitantes/mês, 14 (quatorze) pessoas/dia nos primeiros anos de visitação. Porém, ao longo da pesquisa, as análises mostraram um aumento crescente de visitantes a cada ano. Pode-se observar que, a partir do final da década de 1950, a instituição chegou a registrar, em um único ano, quase três livros inteiros de visitantes, como exemplo, os livros 8,9 e 10, que foram usados para registrar visitantes de 1958, o que indicou um aumento crescente no número de visitantes.

Dois aspectos dificultaram um pouco o levantamento dos dados. O primeiro surgiu com a dificuldade de identificação de grande parte da caligrafia, feita em bico de pena (caneta tinteiro) e com assinaturas ilegíveis ou borradas. Entretanto, no final da década de 1960, a caneta esferográfica começou a ganhar espaço, apresentando, inclusive, novas cores nas assinaturas, para além das azuis e pretas, até então mais recorrentes. O segundo se deu pelo fato bastante comum de o registro ter sido feito por um membro de um grupo familiar, do gênero masculino, e apenas o seu nome ou assinatura e, na sequência, completar com os termos "e senhora", "e esposa" ou "e família".

A partir dessas considerações, o levantamento foi feito dia a dia (linha a linha), mês a mês e ano a ano, de forma que pudesse ser mapeado, ao longo dos vinte anos propostos, os grupos de escolares que visitaram o Museu da Inconfidência. Dessa forma, foi possível descobrir quem era e de onde vinha esse público escolarizado que visitava o museu. Para processar melhor a distribuição geográfica dos visitantes, a região sudeste foi separada pelos seus estados, lembrando que, naquele contexto, o Rio de Janeiro ${ }^{7}$ era a Capital Federal do país. Para a análise dos visitantes do estado de Minas Gerais, destaca-se que os visitantes do estado (público total), eram visitantes preponderantemente originários das cidades de Ouro Preto (e distritos) e Belo Horizonte. Foram registrados também visitantes de outros estados brasileiros e outros países. E também visitantes que se auto declararam como sendo padres, militares, doutores, políticos, engenheiros, e ainda, foco principal da nossa pesquisa, como sendo estudantes e professores.

No primeiro livro, ou seja, o Livro I, em sua folha 1, apenas seis assinaturas referentes ao ano de 1945 foram identificadas, sendo que a data inicial dos registros é de 29 de dezembro de 1945. As linhas seguintes referem-se sequencialmente ao início do ano de 1946, parecendo, assim, que o primeiro livro com registro dos visitantes deveria ter sido planejado para iniciar de fato os seus registros a partir do ano de 1946.

Nesse primeiro livro, as folhas foram divididas em duas colunas, a primeira para registro visitante/nome e a outra para procedência, em que os visitantes registravam, além do local de origem, a data da visita, segundo a Foto 3. Os demais livros apresentavam três colunas distintas, com Nome, Procedência e Data. Logo nas primeiras folhas, foram localizados visitantes, não somente do estado de Minas Gerais, como também de outros estados e países.

Foram incluídos na terminologia "grupos de escolarizados" o público visitante declaradamente originário de instituições educacionais, de qualquer faixa etária, nível escolar,

\footnotetext{
${ }^{6}$ Tal resolução foi encontrada em um documento do setor administrativo daquele ano, nos arquivos da casa do Pilar.
}

${ }^{7}$ O Estado da Guanabara foi contabilizado como pertencente ao Rio de Janeiro. 
gênero, região, formação ou mesmo motivação, que os trouxeram a esta instituição, registrando qualquer evidência que comprovasse essa ligação. Nos vinte anos pesquisados, foram encontrados, nos livros de visitas do Museu da Inconfidência, cerca de 270 (duzentas e setenta) referências a grupos de escolares ou afins.

Foto 3 - Folha do Livro 1 de 29 de dezembro de 1945

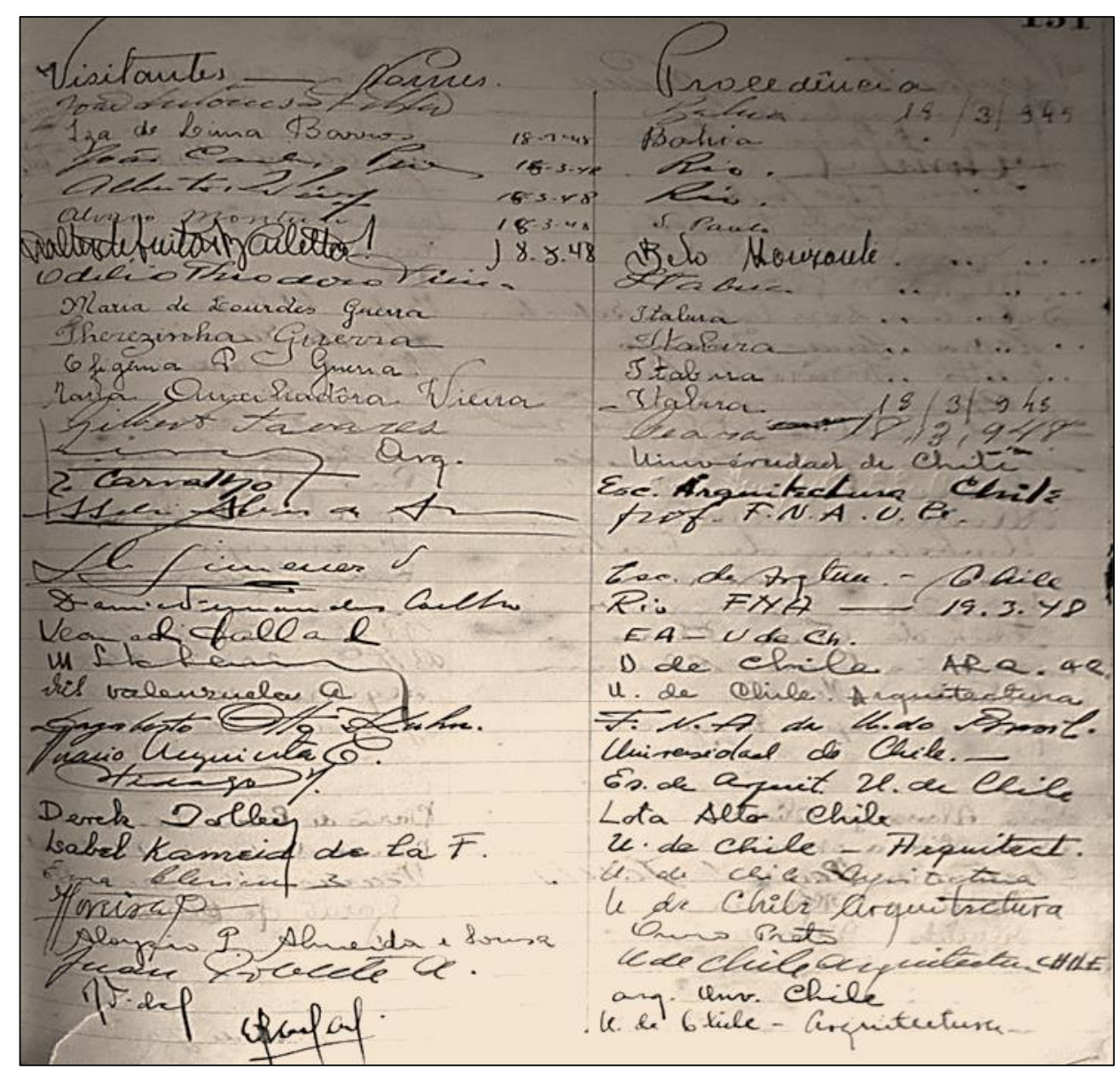

Fonte: Acervo Fotográfico de Betânia dos Anjos do Carmo - 2018.

\section{Grupos de sujeitos ligados a instituições educacionais - aspectos gerais}

O cruzamento das fontes dos ofícios com os livros de visitantes mostrou que muitas escolas trocavam correspondências prévias com o diretor do museu em cada um dos mandatos, manifestando a intenção de visitar o espaço, geralmente como complementação de algum estudo iniciado nas escolas. Das correspondências encontradas e das análises das assinaturas nos livros, o maior número de visitantes de escolares foram da região sudeste, em sua maioria, Minas Gerais, mais especificamente Belo Horizonte, seguidos pelos estados do Rio de Janeiro e São Paulo. Houve muito pouca ocorrência do registro de visitantes do Espírito Santo. Ao longo dos vinte anos, públicos ligados a instituições educacionais estrangeiros também frequentaram o museu. $\mathrm{O}$ primeiro grupo de visitantes identificado como sendo ligados a instituições educacionais veio da capital do estado de Minas Gerais, sendo registrada como a "Caravana de BH do Colégio Marconi" (08/1946, p. 39 F).

\footnotetext{
${ }^{8}$ O Colégio Municipal Marconi (hoje Escola Municipal Marconi) foi fundado em 1937, na cidade de Belo Horizonte, Minas Gerais e seu prédio é um bem tombado em nível municipal (COLÉGIO MUNICIPAL MARCONI, 2018).
} 
Em um breve estudo, o Colégio Marconi de Belo Horizonte foi criado por imigrantes italianos ligados ao movimento integralista ${ }^{9}$. Dentro das propostas da educação integralista, o aspecto de socialização como suporte para o ensino fazia-se presente nas diretrizes do movimento. Um exemplo desta prática foi apontada na dissertação de Lenir Palhares (2016), citando um estudo acerca da Enciclopédia Integralista em que a Divisão de Estudos previa "[...] a formação de uma identidade coletiva e o desenvolvimento do sentimento de pertença [...]". O objetivo era, além da doutrina, a educação esportiva, moral e cívica. Essas práticas eram compostas de programação tais como "[...] visitas a estabelecimentos, fábricas e museus "para desenvolver na criança, não só o amor ao trabalho, como também o gosto artístico"" (ENCICLOPÉDIA, 1959, p. 177-178 apud PALHARES, 2016, p. 111).

Acredita-se que foi por uma atividade escolar que a programação dessa visita trouxe o grupo do Colégio Marconi e outros grupos de escolares a Ouro Preto. A presença deles aparece com registro de vinte e oito participantes, no dia 22 de agosto de 1946. Como as assinaturas parecem ser de adultos, não há como distinguir alunos de professores ou quem foi o responsável pelo grupo, pelo fato de não haver auto declaração nesse sentido. Quanto ao gênero, assinaram um primeiro grupo de vinte homens e, na sequência, oito mulheres. Muitas vezes o responsável pelos alunos não permitia que todos assinassem ou não indicava o número exato de participantes da visita.

Foto 4 - Registro da visita de grupo de escolares do Colégio Marconi em 1946

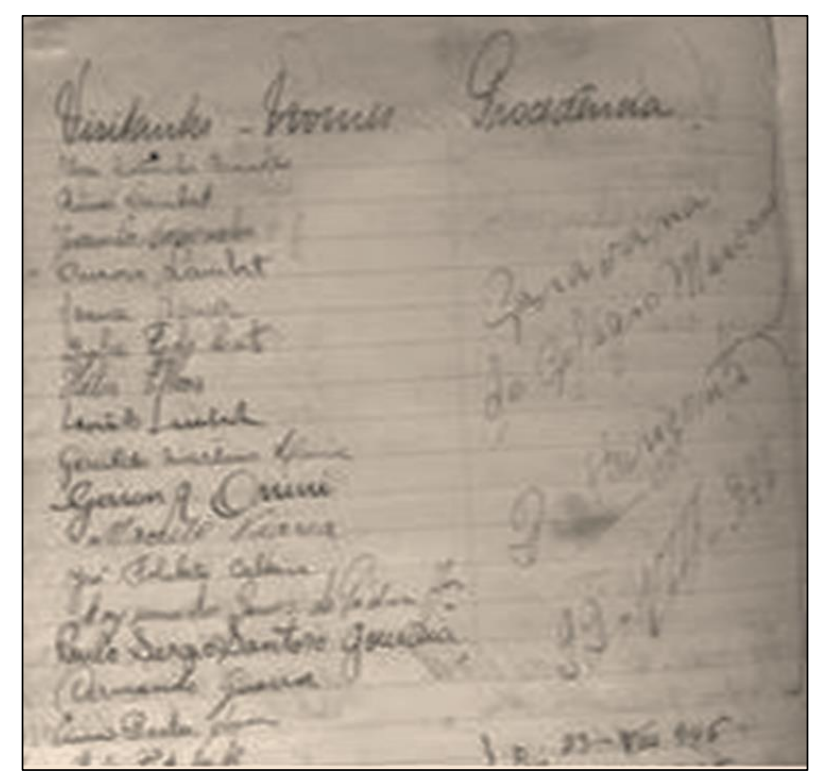

Fonte: Acervo fotográfico de Betânia dos Anjos do Carmo - 2018.

Foram encontrados, no conjunto dos livros pesquisados, visitantes procedentes da França, Argentina, Inglaterra, Bélgica, Itália e vários outros países. Esses visitantes não foram separados por continentes. Dos grupos estrangeiros ligados a instituições, foi constante a presença de escolas e faculdades de Arquitetura e de Direito de diversas regiões e países. Como exemplo dessa variedade institucional, foi encontrado, em agosto de 1962, o registro The Experiment in International Living, uma organização estadunidense, sem fins lucrativos, voltada a programas de educação, desenvolvimento sustentável e intercâmbio, criada em 1932.

\footnotetext{
${ }^{9}$ Ver: PALHARES, Lenir. O integralismo e a educação: um estudo sobre as escolas integralistas em Minas Gerais (1932-1937). 2016. 136f. Dissertação (Mestrado em Educação) - Faculdade de Educação, Universidade Federal de Minas Gerais, Belo Horizonte, 2016.
} 
Com o passar dos anos, já foi possível observar grupos maiores de visitantes do sexo feminino "desacompanhadas" de alguma "autoridade" masculina. Um exemplo disso é uma auto declarada professora, responsável por um grupo de alunas, vindas do Estado da Guanabara, que registrou-se como "Professora da Escola Normal Inácio de Azevedo Amaral, acompanhada de 33 alunas do $2^{\circ}$ ano normal" (ARQUIVO HISTÓRICO DO MUSEU DA INCONFIDÊNCIA, [19--], p. 77). A partir da segunda metade da década de 1950 e principalmente na década seguinte, foi possível identificar a presença mais efetiva da mulher no cenário social, o que refletiu, de alguma forma, nos livros de visita. Um exemplo disso é o registro de um grupo de visitantes composto por um grupo de 25 (vinte e cinco) mulheres, autodeclaradas estudantes, da Universidade Federal Rural do Rio de Janeiro (ARQUIVO HISTÓRICO DO MUSEU DA INCONFIDÊNCIA, [19--], p. 26).

Também foi encontrado dentro de um dos livros, em folha pautada solta, o registro da visita feita por um grupo de mulheres, estudantes do Colégio Sion de São Paulo, em 18 de outubro de 1962, acompanhadas de uma religiosa, prestando homenagem às duas figuras femininas ligadas à Inconfidência Mineira, Bárbara Heliodora (1759-1819) e Marília de Dirceu (1767-1853), com os seguintes dizeres: "Homenagem à Bárbara Heliodora e Marília de Dirceu feita pelo Colégio Sion (São Paulo), sob a direção da Irmã Germana - Caravana dirigida pelo expositor cultural Estudantil Prof. Dr. Alceu Manard Araújo em 18/10/1962"10 (ARQUIVO HISTÓRICO DO MUSEU DA INCONFIDÊNCIA, [19--]).

Foto 4 - Homenagem de alunas do Colégio Sion (SP) às mulheres da Inconfidência Mineira, em 1962

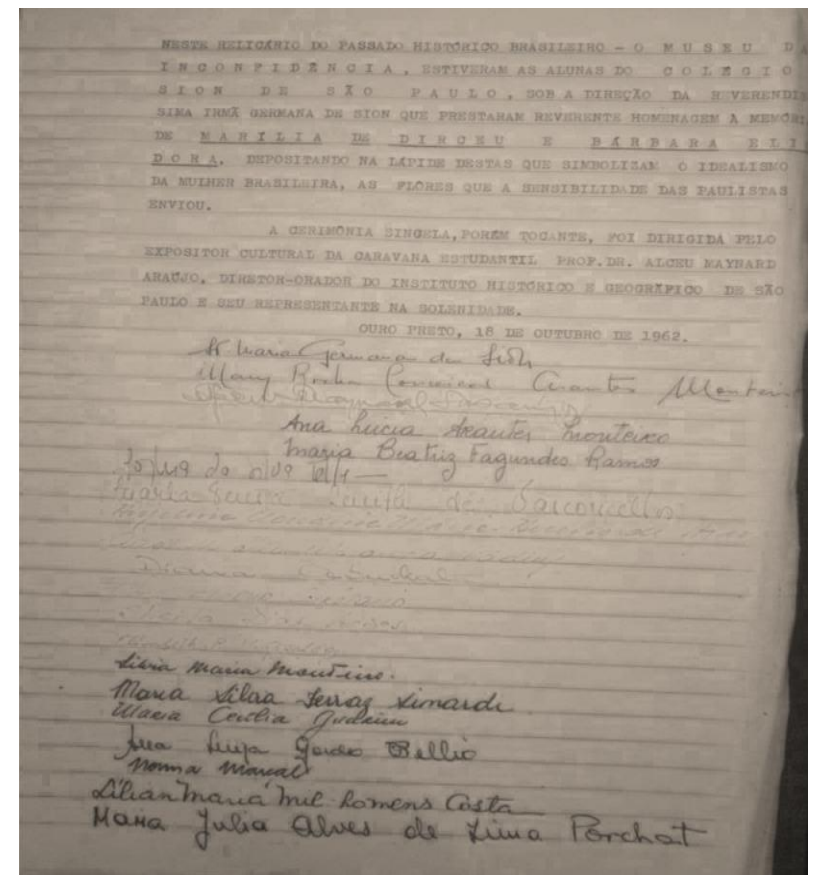

Fonte: Acervo Fotográfico de Betânia dos Anjos do Carmo - 2018

\section{Visitantes por ano}

Nos anos de 1944 e 1945 não foi registrada a presença nos livros de visitantes de nenhum grupo de escolares, embora isso não signifique que estes não tenham visitado o museu. Em uma análise ano a ano, os quatro menores índices de visitantes escolares foram os anos de 1946, com apenas três registros de público escolar; seguido dos anos de 1961, com 4

\footnotetext{
${ }^{10}$ Informações extraídas do Livro 10/1962 do Arquivo Histórico do Museu da Inconfidência ([19--)].
} 
(quatro); 1947 e 1953, com 5 (cinco), e os anos de maior visitação foram os anos de 1960, com 32 (trinta e duas), 1962 com 29 (vinte e nove), 1965 com 26 (vinte e seis) e 1964, com 25 (vinte e cinco) registros de público visitante escolar. Conforme ressaltamos inicialmente, o livro que contempla o período entre 26 de junho de 1964 a 02 janeiro de 1965 não foi localizado. A não contabilização desse período coloca em dúvida qual seria de fato o ano de maior número de visitantes, mas não compromete substancialmente as demais análises.

Observando o recorte temporal compilado em meses, constatou-se que os meses de julho e agosto foram os mais visitados, contra março e dezembro que receberam um menor público. Pode ser que a maior incidência nesses meses esteja relacionada às férias escolares do meio do ano e ao período de estio, considerando que no fim de ano, embora já fosse período de férias, além das festas, geralmente era também um período muito chuvoso para viagens em Minas Gerais.

\section{Visitantes por região}

Para esta análise específica de grupos de escolares, eliminando as ocorrências indistintas, considera-se o total de 270 (duzentos e setenta) apontamentos. Desses, ao se verificar os visitantes de escolares por estados e países, 95\% (noventa e cinco por cento) foram visitantes do Brasil e 5\% (cinco por cento) estrangeiros.

No Brasil, a região sudeste aparece com $74 \%$ (setenta e quatro por cento) de visitação, sendo o estado de Minas Gerais com o maior percentual, 52,2\% (cinquenta e dois inteiros e dois décimos por cento). Rio de Janeiro e São Paulo registraram cada um 22,5\% (vinte e dois inteiros e cinco décimos por cento) de visitas ao Museu, enquanto o Espírito Santo apresentou apenas $2,8 \%$ (dois inteiros e oito décimos por cento) das visitas.

As outras regiões do país totalizaram $21 \%$ (vinte e um por cento) de visitantes dos 270 (duzentos e setenta) considerados. A distribuição dividiu-se entre 43,5\% (quarenta e três inteiros e cinco décimos por cento) da região nordeste, região sul com $41,0 \%$ (quarenta e um por cento), a região centro-oeste registra $12,8 \%$ (doze inteiros e oito décimos por cento) e o norte apresenta $2,7 \%$ (dois inteiros e sete décimos por cento) dos visitantes.

Esses números mostram que a região sudeste foi a região que mais visitou o museu neste período. Porém, dentro da região mais presente, o Espírito Santo teve, em termos percentuais, uma visitação semelhante à região norte do país, 2,8\% (dois inteiros e oito décimos por cento) e 2,7\% (dois inteiros e sete décimos por cento) respectivamente, que, somados, resultam em um número de visitantes muito próximo ao público estrangeiro no mesmo período, $5 \%$ (cinco por cento). É um resultado que coloca em cheque a justificativa de não visitar o museu por questões geográficas, uma vez que alguns grupos de escolares de outros países dispuseram-se a vir conhecer a cidade e o Museu da Inconfidência, como vimos anteriormente. Esse fato pode sugerir que os deslocamentos em um país de dimensões continentais eram (e ainda são) muito difíceis e caros.

\section{Visitantes por gênero}

Para essa análise, serão feitas algumas considerações para esclarecer os critérios que se estabeleceram para a avaliação de gênero no registro dos livros de visitantes. Quando se começou a fazer o levantamento do número de docentes do sexo masculino e feminino por meio das auto declarações, foram encontradas subjetividades que colocavam em dúvida o número exato de homens e mulheres de alguns grupos de visitantes, uma vez que nem sempre o registro deixava clara a condição dos visitantes. Como exemplo dessa situação, identificamos um grupo que visitou o Museu em julho de 1952 (ARQUIVO HISTÓRICO DO MUSEU DA INCONFIDÊNCIA, [19--], p. 76) e escreveu: "34 professores do $10^{\circ}$ Curso Rural da Fazenda 
do Rosário de Ibirité" ou ainda, "16 visitantes da França - Representantes do Colégio Sorbonne", em setembro de 1952 (ARQUIVO HISTÓRICO DO MUSEU DA INCONFIDÊNCIA, [19--], p. 91). Nesse caso, apesar de estar claro ser um grupo de sujeitos ligados à educação, por se tratar de uma referência comum aos dois gêneros, optou-se por não contabilizar o grupo.

Quando se tratava de grupos de escolares, de instituições específicas, como escolas militares ou colégios religiosos, em que havia algum tipo de autodeclaração que indicasse o gênero, por patente ou grau religioso, considerou-se válido na contagem a referência masculina ou feminina, conforme o caso. Um exemplo seria um grupo do Uruguai que escreveu: "Excursion de las Franciscanas [...] de Maria - Colegio de La Asunción con las alumnas [...]" em julho de 1963 (ARQUIVO HISTÓRICO DO MUSEU DA INCONFIDÊNCIA, [19--], p. 31), em que, pelo critério adotado, essas alunas foram acompanhadas por uma pessoa também do sexo feminino. Outro caso seria a visita de um grupo de escolares de um colégio militar de Belo Horizonte, em que os alunos foram acompanhados por um Capitão Diretor e uma Capitã Professora, auto intitulada como "Embaixada de alunos do Ginásio Tiradentes da Polícia Militar do Estado de Minas Gerais", que visitaram o Museu em maio de 1954 (ARQUIVO HISTÓRICO DO MUSEU DA INCONFIDÊNCIA, [19--], p. 180). Nesse caso, foram considerados um acompanhante do sexo masculino e uma do sexo feminino.

Da mesma forma, no caso de o registro que apareceu como um grupo de forma geral, como "Professoras do Colégio Nossa Senhora das Neves" (ARQUIVO HISTÓRICO DO MUSEU DA INCONFIDÊNCIA, [19--], p. 45) ou "Grupo escolar do Rio de Janeiro acompanhado de seus diretores - Caravana do Colégio Brasil - Órgão Estudantil de Niterói" (ARQUIVO HISTÓRICO DO MUSEU DA INCONFIDÊNCIA, [19--], p. 99), foi considerada representante daquele grupo somente uma pessoa do sexo registrado. No primeiro exemplo, uma do sexo feminino e, no segundo, um representante do sexo masculino.

Definidos esses parâmetros, foram contabilizados 205 (duzentas e cinco) ocorrências de gêneros, dos quais $68,7 \%$ (sessenta e oito inteiros e sete décimos por cento) foram do sexo masculino e $31,35 \%$ (trinta e um inteiros e trinta e cinco décimos por cento) do feminino. Os percentuais apontam para um número muito maior de visitantes autodeclarados professores do sexo masculino que visitaram o Museu em vinte anos, quer por visitas individuais, em grupos de professores ou acompanhando caravanas de alunos. Isso sugere que professores do gênero masculino predominaram nas visitas ao museu, uma vez que também predominavam como professores do ginasial, científico e cursos superiores, naquele período.

\section{Visitantes por instituições}

Para o estudo dos visitantes ligados a instituições com o registro da presença nos livros de visitantes do museu, procurou-se dividir os grupos entre instituições estrangeiras e nacionais, separando-as por categorias: a primeira como universidades/faculdades (ensino superior); a segunda, ginásios/colégios, grupos de escolares/escolas. Considerou-se também nesse último grupo de visitas de estudantes ou professores que vieram individualmente, como forma de lazer. Mesmo que estivesse claro que estavam ali somente a passeio turístico, considerou-se a informação da instituição de origem da qual vinham, já que estes a declararam. Um exemplo foi o registro de casais, reconhecidos pelo fato de terem o mesmo sobrenome, e um deles se autodeclarar professor ou professora, como um professor dos Estados Unidos registrou em junho de 1964 (ARQUIVO HISTÓRICO DO MUSEU DA INCONFIDÊNCIA, [19--], p. 110), "Prof. and Mrs. Alan M. Mac. Ewan - Lincoln University Penn". Nesse caso, o que importou foi o registro da condição auto declarada de ser docente de uma universidade estrangeira.

Para o ensino superior, foram incluídos todos os registros nos quais constavam termos como: faculdade, escola de ensino superior, escola superior, escola nacional, universidade, 
engenharia, entre outras. Em seguida, foram classificados como um segundo grupo os visitantes que se afirmaram ser de escolas de ensino primário, colegial e científico, bem como escolas técnicas, politécnicas, profissionalizantes, colégios, ginásios, escola normal, internato.

A dificuldade nessa triagem foi com os registros em que foram colocados somente o nome da instituição sem maiores esclarecimentos, como a "Caravana da Escola 12 de Dezembro de Belo Horizonte" (ARQUIVO HISTÓRICO DO MUSEU DA INCONFIDÊNCIA, [19--], p. 108). Houve também o problema da não indicação da faixa etária ou nível escolar dos estudantes, como o grupo de "15 pessoas que faziam parte de uma delegação de estudantes do Peru” (ARQUIVO HISTÓRICO DO MUSEU DA INCONFIDÊNCIA, [19--], p. 188). Nesses casos, por se entender que a suposição poderia levar a uma interpretação equivocada, a opção foi enquadrar essas instituições como "sem maiores informações".

\section{Concluindo}

Foram encontrados e validados, entre as 270 (duzentas e setenta) referências a grupos de escolares, 180 (cento e oitenta) registros ligados a instituições educacionais. Do total de 180, 41,65\%, ou seja, 75 (setenta e cinco) eram visitantes de ensino superior, divididos entre instituições nacionais e estrangeiras. Deste grupo, a maioria era estudantes dos cursos de Direito, Filosofia, Arquitetura e Belas Artes. Enquadrados como nível primário, colegial e científico foram localizados, 48,33\% ocorrências, ou seja, 87 (oitenta e sete) grupos. Cerca de $10 \%$ das instituições, 18 delas, eram ligadas a instituições não escolares, como grupos escoteiros ou grupos escolares em cursos de férias. Foram registrados muitos grupos ligados a instituições religiosas ou colégios militares, porém, optou-se por não contabilizá-las separadamente uma vez que muitas escolas adotavam nomes de cunho religioso ou cívico, o que dificulta uma triagem clara para determinar como sendo escolas públicas ou particulares, ou ainda militares ou civis. E o mais impactante, embora esperado, foi a rarefeita visita de grupos de escolares da cidade de Ouro Preto, Mariana ou outras com maior proximidade geográfica.

Constatou-se que a maioria do público escolarizado era de brasileiros e oriundos da região sudeste do país. O visitante do gênero masculino se sobrepôs ao grupo feminino, muito embora tenha sido observado um crescente número de grupos de mulheres visitando o museu nos últimos anos da pesquisa. Chamou a atenção os grupos de escolares estrangeiros e nacionais ligados às escolas de Arquitetura e Belas Artes e ainda os frequentes registros da Escola de Tradutores e Intérpretes de Minas Gerais, sempre presentes nos livros ao longo de todo o período estudado, certamente acompanhando estrangeiros.

Acredita-se que os visitantes escolares procuravam o museu com o objetivo de conhecer parte da história do Brasil ali representada, uma vez que foi localizada, nos livros, em vários momentos, a formalização dos responsáveis pelos grupos, acerca da importância do fato histórico, de seus personagens e da cidade em si. Thais Nivia de Lima Fonseca afirma que a Inconfidência Mineira tem sido um "[...] elemento de suporte a uma determinada construção historiográfica e a projetos e posicionamentos políticos desde as últimas décadas do século XIX [...]". Para a autora, “[...] Tiradentes desponta como seu símbolo, síntese das idéias das quais o movimento seria o precursor, no Brasil. [...]" (FONSECA, 2002, p. 57). As constantes visitas das escolas militares ao Museu da Inconfidência poderiam ser justificadas pelo fato de, em 29 de abril de 1946, o Presidente Eurico Gaspar Dutra ter instituído o dia 21 de abril como Dia das Polícias Militares e Civis, considerando Joaquim José da Silva Xavier, o Tiradentes, como o mártir da Independência e lhe conferindo o título de Patrono Cívico da Nação e das Polícias Militares e Civis do Brasil.

Percentual e proporcionalmente, viu-se que a maioria dos grupos de escolares que visitaram o museu, entre 1945 e 1965, foram de pessoas com nível superior e médio, de 
escolas particulares, religiosas, militares e profissionalizantes, em sua maioria do sexo masculino. Esse perfil corrobora com a ideia de que a educação e a cultura previstas nas constituições e pensadas para o Brasil, naquele período, pretendiam alcançar um público social em geral, e escolar em particular. Entretanto, na realidade, aqueles que frequentavam a escola representavam uma pequena parte da população brasileira, uma vez que, de acordo com Maria Luisa Santos Ribeiro, da década de 1930 à 1960, não ocorreram avanços efetivos na educação no país. Segundo a autora, "[....] o Brasil chegou à década de 60 do século XX com quase $40 \%$ de analfabetismo, o que evidencia a ineficiência das reformas, o seu caráter retórico e a omissão do Estado no cumprimento efetivo das leis que ele próprio editara" (RIBEIRO, 1986, 161). Isso mostra que, de fato, o aluno ou professor, que tinha a possibilidade de visitar o museu, era um sujeito dotado de um duplo privilégio: o de ser escolarizado e de ter as condições materiais para visitar o museu.

\section{REFERÊNCIAS}

ABREU, Regina. A Fabricação do imortal: memória, história e estratégias de consagração no Brasil. Rio de Janeiro: Rocco, Lapa, 1994. https://doi.org/10.1590/s0104$\underline{93131997000200008}$

\section{ARQUIVO HISTÓRICO DO MUSEU DA INCONFIDÊNCIA. Livros de visitação da Casa} do Pilar. Ouro Preto, [19--].

BRUSADIN, L. B. O Museu da Inconfidência em Ouro Preto (MG) e sua interface com o turismo, o patrimônio e a comunidade local. Rio de Janeiro: [s.n.], 2014.

CARMO, Betânia dos Anjos do. O Museu da Inconfidência e as marcas da educação nos livros de visitantes (1945-1965). Dissertação (Mestrado em Educação). Programa de Pós Graduação em Educação - PPGE do Departamento de Educação - DEEDU, da Universidade Federal de Ouro Preto - Mariana, 2018. https://doi.org/10.29280/rappge.v2i2.4342

CARVALHO, José Murilo de. A formação das almas: o imaginário da República no Brasil. São Paulo: Companhia das Letras,1990. https://doi.org/10.29078/rp.v0i36.41

COELHO, Priscilla Arigoni. Metáforas em rede no processo de institucionalização: um estudo sobre memória e discurso da museologia no Brasil (1932 a 1985). Universidade Federal do Estado do Rio de Janeiro. Centro de Ciências Humana e Sociais. (Tese de doutorado em Memória Social). 2015. 360 f.. https://doi.org/10.1590/1807-01912016223524

FONSECA, Thais Nivia de Lima e. A Inconfidência Mineira e Tiradentes vistos pela imprensa: a vitalização dos mitos (1930-1960). Rev. Bras. Hist., São Paulo, v.22, n.44, p.439-462, 2002. Disponível em <http://www.scielo.br/ scielo.php?script =sci_arttext\&pid= S0102-01882002000200009\&lng=pt\&nrm=iso>. Acesso em 08 fev. 2019. https://doi.org/10.1590/s0102-01882002000200009

GATTI, Bernadete. A. Estudos quantitativos em educação. Educação e Pesquisa, São Paulo, v.30, n.1, p.11-30, jan./abr. 2004. Disponível em: http://www.scielo.br/pdf/ep/v30n1/ a02v30n1.pdf. Acesso em: 03 jun. 2018. https://doi.org/10.1590/s1517-97022004000100002

HALBWACHS, Maurice. A Memória Coletiva. Tradução de Beatriz Sidou. 2. ed. São Paulo: Ed. Centauro, 2013. 
JULIÃO, Letícia. Apontamentos sobre a história do museu. 2. ed. Brasília: Caderno de diretrizes museológicas, 2006, p. 17-30.

LE GOFF, Jacques. História e Memória. São Paulo: Unicamp. 2003.

RIBEIRO, M. L. S. História da educação brasileira: a organização escolar. 6. ed. São Paulo: Moraes. 1986

ROCHA, M. B. M. Tradição e modernidade: o processo constituinte de 1933/34. In: FÁVERO, Osmar. (Org.). A Educação nas constituintes brasileiras: 1823-1988. 2. ed. Campinas: Autores Associados, 1996, p. 119-138.

ROMANO, Luís. Manuel Bandeira e Cecília Meireles em Ouro Preto. Revista Turismo \& Desenvolvimento, s.d., v.1, n. 27/28, p. 1127-1139, 2017. Disponível em: <http://revistas.ua.pt/index.php/rtd/article/view/7095/5583>. Acesso em: 12 jun. 2018. https://doi.org/10.22533/at.ed.27919150411

VEIGA, Cynthia Greive. História da Educação. São Paulo: Ática, 2007. 